ABDIMAS: Jurnal Pengabdian Masyarakat Universitas Merdeka Malang
Vol.5(3) November 2020, 266-278
p-ISSN: 2721-138X | e-ISSN: 2548-7159
http://jurnal.unmer.ac.id/index.php/jpkm

\title{
PPUPIK Unit Produksi Mesin Otomatis bagi UMKM Pangan untuk Meningkatkan Standar Mutu Produk Pangan
}

\author{
Harsawardana', Maria Ulfah', Bayu Samodra², Antonius Budi Suharyono² \\ ${ }^{1}$ Institut Pertanian Stiper (Instiper), Jl. Nangka II, Depok, Yogyakarta, 55281, Indonesia \\ ${ }^{2}$ BioTechnik-Innovation, Atomation \& Mechatronics Development Center \\ Jl. Gejayan Gang Narada 3, Yogyakarta, 55281, Indonesia
}

Article Info:

Received: 2020-08-14 Revised: 2020-09-06

Accepted: 2020-10-31

\section{Keywords :}

Agro-industrial;

Business center; Food industry; Machinery and equipment

\begin{abstract}
This campus intellectual product business development activity aims to develop a Pilot Plan and workshop business as a production center for agro-industrial machinery and equipment that can provide opportunities and work experiences to students of the Agricultural Engineering Study Program, Stiper Agricultural University and encourage the development of an environmen utilizing research results from the lectures and researchers at the Stiper Agricultural University. Another objective is to transfer agro-industrial technology to small and medium-scaled industries and cooperatives in the food sector. PPUPIK programs is focusing on service activities, production of automatic machine and equipment for smallscaled food industry. Even though the program could need the demand of other agro-industries. The methods of implementing this activity are training, consultation, machine and equipment fabrication, as well as feasibility testing of agro-industrial machines and equipment. Through this activity, it has succeeded in establishing a business institution to increase campus income and entrepreneurial training places for final semester students and has succeeded in producing and selling 17 units of agro-industrial equipment machines and has held four trainings from May 2019 to the month July 2020.
\end{abstract}

(C) 2020 Published by University of Merdeka Malang. This is an open access article distributed under the CC BY-SA 4.0 license (https://creativecommons.org/licenses/by-sa/4.0/)

How to cite: Harsawardana, Ulfah, M., Samodra, B., \& Suharyono, A. B. (2020). PPUPIK Unit Produksi Mesin Otomatis bagi UMKM Pangan untuk Meningkatkan Standar Mutu Produk Pangan. Abdimas: Jurnal Pengabdian Masyarakat Universitas Merdeka Malang, 5(3), 266-278. https://doi.org/10.26905/abdimas.v5i3.4662

\section{PENDAHULUAN}

Kegiatan pengembangan usaha produk inteketal kampus ini (PPUPIK) bertujuan untuk mengembangkan usaha Workshop Pilot Plan sebagai pusat produksi mesin dan peralatan agroindustri yang dapat memberikan kesempatan dan pengalaman kerja kepada mahasiswa Program Studi Teknik Pertanian, Institut Pertanian Stiper guna mengembangkan budaya kewirausahaan perguruan tinggi, menciptakan akses bagi terciptanya wirausahawan baru, menunjang otonomi kampus melalui perolehan pendapatan mandiri, 
memberi kesempatan pengalaman kerja kepada mahasiswa, mendorong berkembangnya budaya pemanfaatan hasil riset perguruan tinggi bagi masyarakat (Afrianto, 2010). Usaha yang telah dilakukan selama ini adalah usaha pembuatan mesin peralatan agroindustri, tetapi mengingat situasi dan kondisi industri UM KM pangan saat ini, maka usaha yang difokuskan dalam kegiatan pengabdian / PPUPIK ini adalah produk mesin dan peralatan otomatis untuk UMKM industri pangan.

Cara Produksi Makanan yang Baik (CPMB) atau Good Manufacturing Practices (GMP) adalah suatu pedoman cara berproduksi makanan yang bertujuan agar produsen memenuhi persyaratan-persyaratan yang telah ditentukan untuk menghasilkan produk makanan bermutu dan sesuai dengan tuntutan konsumen (Maligan \& Hermanto, 2017; Erlindawati et al., 2011). Hal tersebut perlu didukung dengan mesin dan peralatan agroindustri untuk mengolah pangan yang memenuhi kriteria yaitu tidak mengandung cemaran logam berat seperti Pb (timbal), Cd (cadmium), As (arsenikum), $\mathrm{Hg}$ (merkuri) dan terbuat dari logam food grade (Sundari et al., 2016; Rahayu \& Rustiani, 2013).

Kendala proses penyangraian di Indonesia saat ini adalah ketidaksempurnaan proses dengan memakai mesin sangrai yang belum memenuhi standar juga menjadi fokus kegiatan PPUPIK ini. Karena penyangraian mempunyai peranan penting dalam proses pengolahan kopi, karena pada tahap ini mempunyai andil 25\% menentukan aroma dan perisa kopi (Hariyanto et al., 2019; Mengani, 2019; Nasution et al., 2018). Selain itu PPUPIK juga menghasilkan pembuatan horizontal feed mixer, pembuatan screw conveyor, dan pembuatan mesin roll pipa, dimana menurut Sufiyanto (2020), proses roll bending pipa dibuat diantaranya untuk menghindari terjadinya cacat kerut (wringkle) dan cacat tekuk (buckling).

Saat ini banyak industri UMKM pangan yang kurang memperhatikan higienitas dan mutu produk mereka, sehingga banyak industri UMKM pangan yang kesulitan atau bahkan tidak bisa mendapakan sertifikat SNI 01-3723-1995, MD-BPOM, P-IRT dan sertifikat Halal MUI. Dengan tidak adanya sertifikat standar mutu pangan, maka produk-produk pangan dari industri UMKM tersebut sulit untuk bersaing di pasar modern dan pasar impor, dan umumnya hanya terbatas di pasar tradisional saja dengan lingkup yang sempit.

Program ini bertujuan untuk memberikan pelatihan pembuatan peralatan sebagai pendukung sektor agroindustri yang dapat dimanfaatkan untuk UMKM di Indonesia. Industri mesin peralatan jarang/tidak ada yang mengembangkan mesin peralatan yang memungkinkan industri pangan UMKM mendapatkan sertifikat dan standar industri pangan. Salah sat aspek penting dalam proses industri pangan yang merupakan syarat sertifikasi dan standar adalah dihindarinya kontak yang terlalu sering manusia dangan bahan dan mesin selam proses berlangsung. Unit produksi ini di Instiper yang disebut dengan pusat inovasi teknologi terapan berusaha mengisi kebutuhan mesin peralatan otomatis untuk tingkat UM KM industri pangan.

\section{METODE}

Waktu dan tempat pelaksanaan Program Pengembangan Usaha Produk Intelektual Kampus (PPUPIK) ini telah dilaksanakan selama 8 bulan yang dimulai sejak bulan Mei hingga Desember 2019 pada tahun pertama dan saat ini sudah memasuki tahun pelaksanaan kedua berjalan hingga Juli 2020. 
ABDIMAS: Jurnal Pengabdian Masyarakat Universitas Merdeka Malang Volume 5, No 3, November 2020: 266-278

Kegiatan pada tahun pertama dan tahun kedua ini melibatkan 8 orang mahasiswa semester akhir dalam bentuk pelatihan dan pemagangan kewirausahaan dengan 2 dosen pembimbing, 1 orang instruktur workshop, 3 orang teknisi dan 1 orang supervisi. M etode pelaksanaan kegiatan meliputi pelatihan, konsultasi dan kerja praktek pada berbagai unit kegiatan (untuk mahasiswa magang), fabrikasi mesin dan peralatan, serta uji kelayakan mesin dan peralatan agroindustri.

Program kegiatan ini adalah memproduksi, menjual, dan melayani pesanan mesin peralatan agroindustri untuk UM KM pangan dan UMKM non pangan sebagai kegiatan manufakturing sedangkan dalam bidang jasa, melayani konsultasi, dan bimbingan teknis dalam pembuatan mesin peralatan agroindustri pangan untuk UMKM

\section{Bahan Baku}

Pada tahun pertama bahan baku untuk produksi sudah dipasok oleh mitra pemasok sejak awal berdirinya pilot plan project sebagai berikut: (1) PT Environeer Semarang sebagai penyedia bahan berupa aluminium ekstrusi food grade, linear rail set, plat stainless steel, dan bahan baku food grade lainnya; (2) PT Panca Manunggal Wiradinamika Semarang sebagai penyedia perlengkapan hidrolik, tabung hidrolik dan komponen kontrol elektronik; (3) UD Sekawan Teknik Yogyakarta sebagai penyedia peralatan yang umum dipakai misalnya baut, plat L, electromotor, gaerbox reducer, cat, elektroda las, dan lain sebagainya.

Pada tahun kedua bahan baku custom spare part selain yang sudah ada dikembangkan dalam bentuk rantai pasok (supply chain) seperti pada Gambar 1.

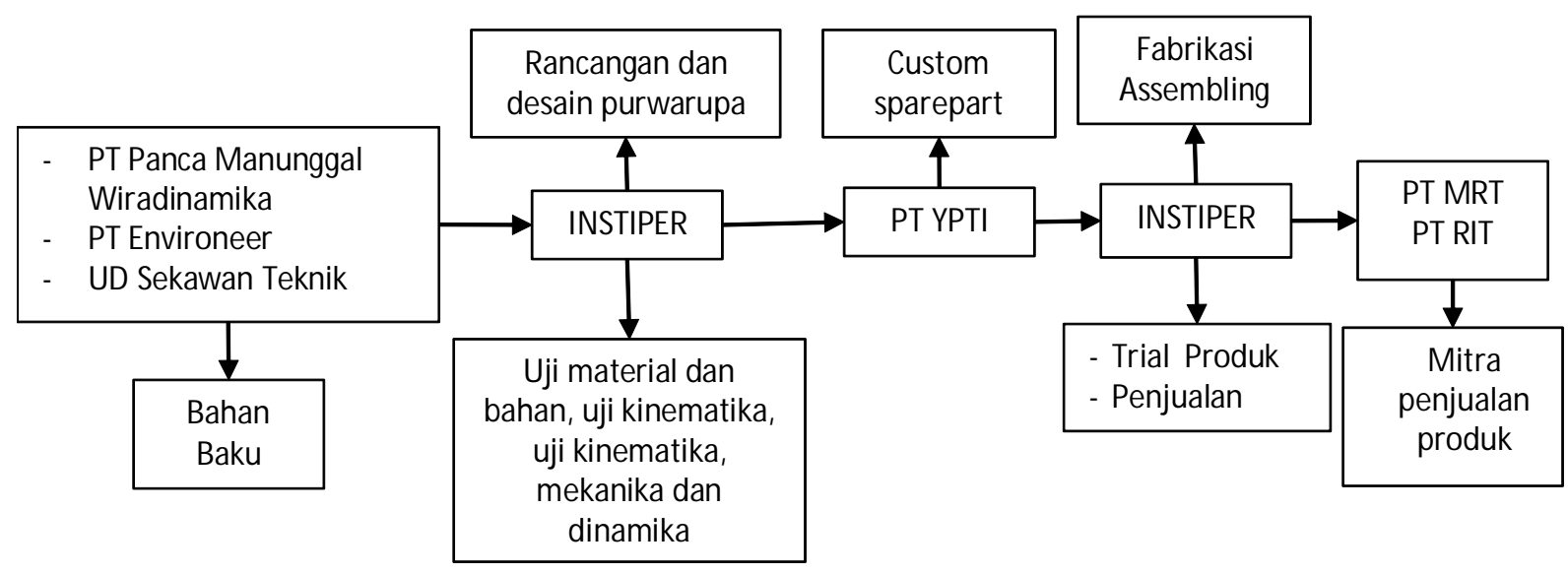

Gambar 1. Rantai pasok (supply chain) bahan baku

\section{Sarana dan Prasarana Produksi}

Untuk kegiatan produksi mesin peralatan agaroindustri pangan pada kegiatan PPUPIK ini mnggunakan fasilitas dan peralatan yang telah dimiliki Workshop Pilot Plan Project/Unit Produksi. 
Tabel 1. Sarana dan prasarana yang dimiliki Workshop Pilot Plan Project /Unit Produksi

\begin{tabular}{llc}
\hline No & \multicolumn{1}{c}{ Investasi yang dimiliki } & Volume \\
\hline A & Bangunan dan Prasarananya & \\
1. Kantor & $500 \mathrm{~m}^{2}$ \\
2. Bengkel & $700 \mathrm{~m}^{2}$ \\
3. Laboratorium kopi \& kakao & $100 \mathrm{~m}^{2}$ \\
4. Bangunan Genset & 1 unit \\
5. Jalan dan penerangan & 1 unit \\
6. Pagar pengaman & 1 unit \\
7. Listrik PLN 5500VA & \\
8. Pendukung lainnya & \\
Sarana transportasi & \\
1. Mobil pick up & 1 bh \\
2. Sepeda motor & 2 bh \\
Peralatan & \\
1. Mesin CNC cutting & 1 unit \\
2. Mesin Bor duduk & 1 unit \\
3. M sein Bor tangan & 2 unit \\
4. Mesin Gerinda tangan & 2 unit \\
5. Mesin Circle cutting & 2 unit \\
6. Mesin Kompresor & 1 unit \\
7. Las listrik & 3 unit \\
8. Las LPG & 1 set \\
9. Kunci baut & 2 set \\
10. Katrol & 1 set \\
11. Komputer Desain & 4 unit \\
12. Generator set & 1 unit \\
13. Mesin milling & 1 unit \\
14. Mesin bubut manual & 2 unit \\
15. Peralatan Keselamatan kerja & \\
Inventaris Kantor & \\
1. Meja & 5 bh \\
2. Kursi & 5 bh \\
3. Lemari & 3 bh \\
4. Rak & 3 bh \\
\hline
\end{tabular}
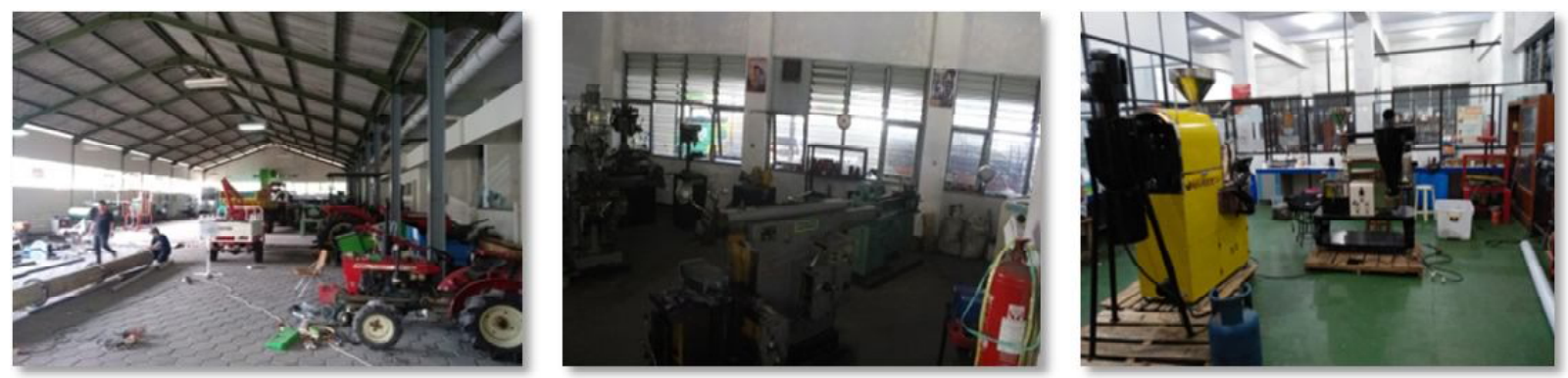

Gambar 2. Gedung workshop dan peralatan produksi 
ABDIMAS: Jurnal Pengabdian Masyarakat Universitas Merdeka Malang Volume 5, No 3, November 2020: 266-278
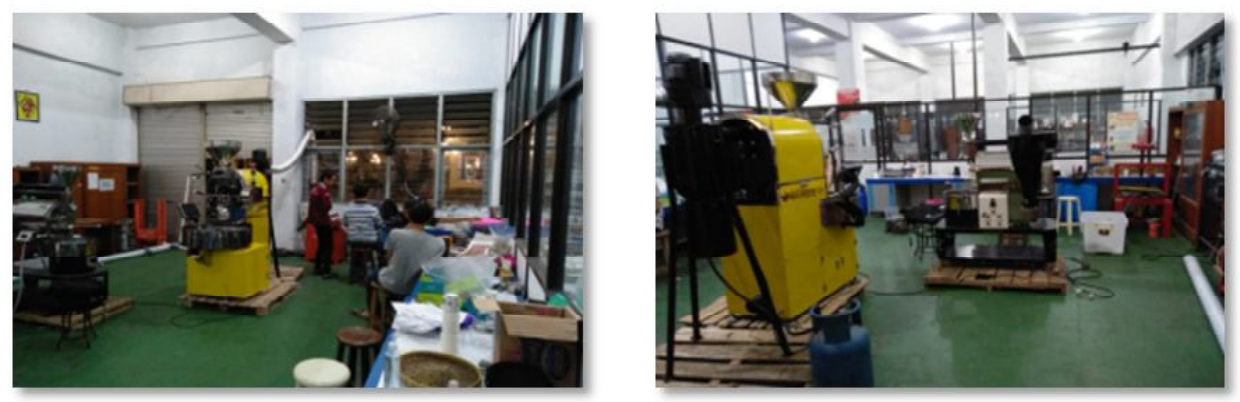

Gambar 3. Laboratorium kopi dan kakao

Selain memanfaatkan fasilitas bengkel dan mesin produksi yang dimiliki, Unit Produksi mesin peralatan ini juga menjalin kerja sama manufakturing dengan bebarapa mitra industri, untuk kelangsungan usaha dan produksi, sebagaimana digambarkan dalam Gambar 4.

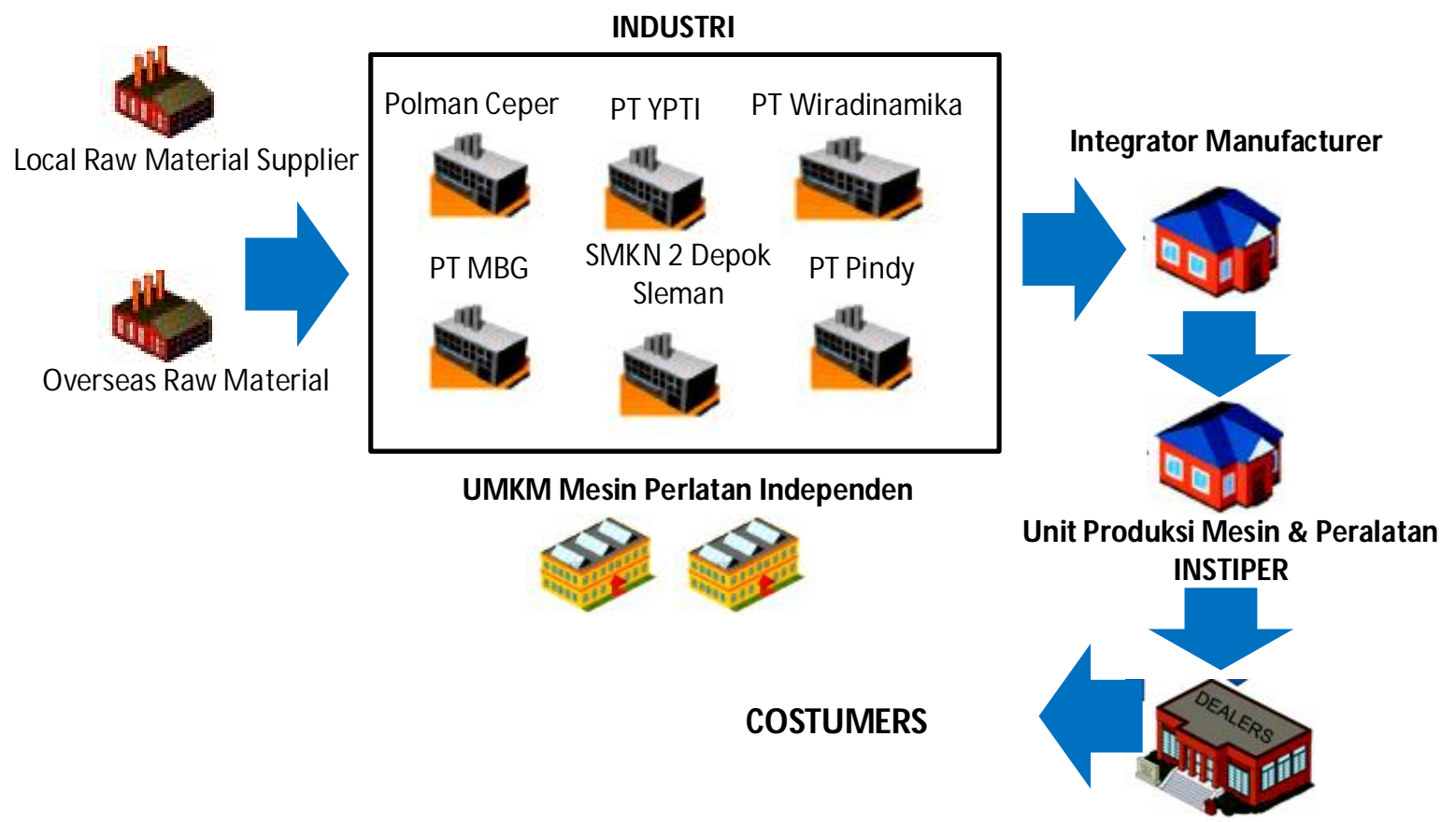

Gambar 4. Struktur manufakturing mesin dan peralatan Instiper

\section{Manajemen}

Pelaksanaan akan dijalankan secara managemen proyek teknologi dengan membentuk IPM (Integrated Project Management) sehingga pelaksanaan kegiatan mulai dari awal dan akhir akan berjalan baik dan sesuai dengan target. Adapun struktur organisasi yang dibentuk juga mengacu kepada format IPM sebagaimana ditunjukkan pada Gambar 5. 


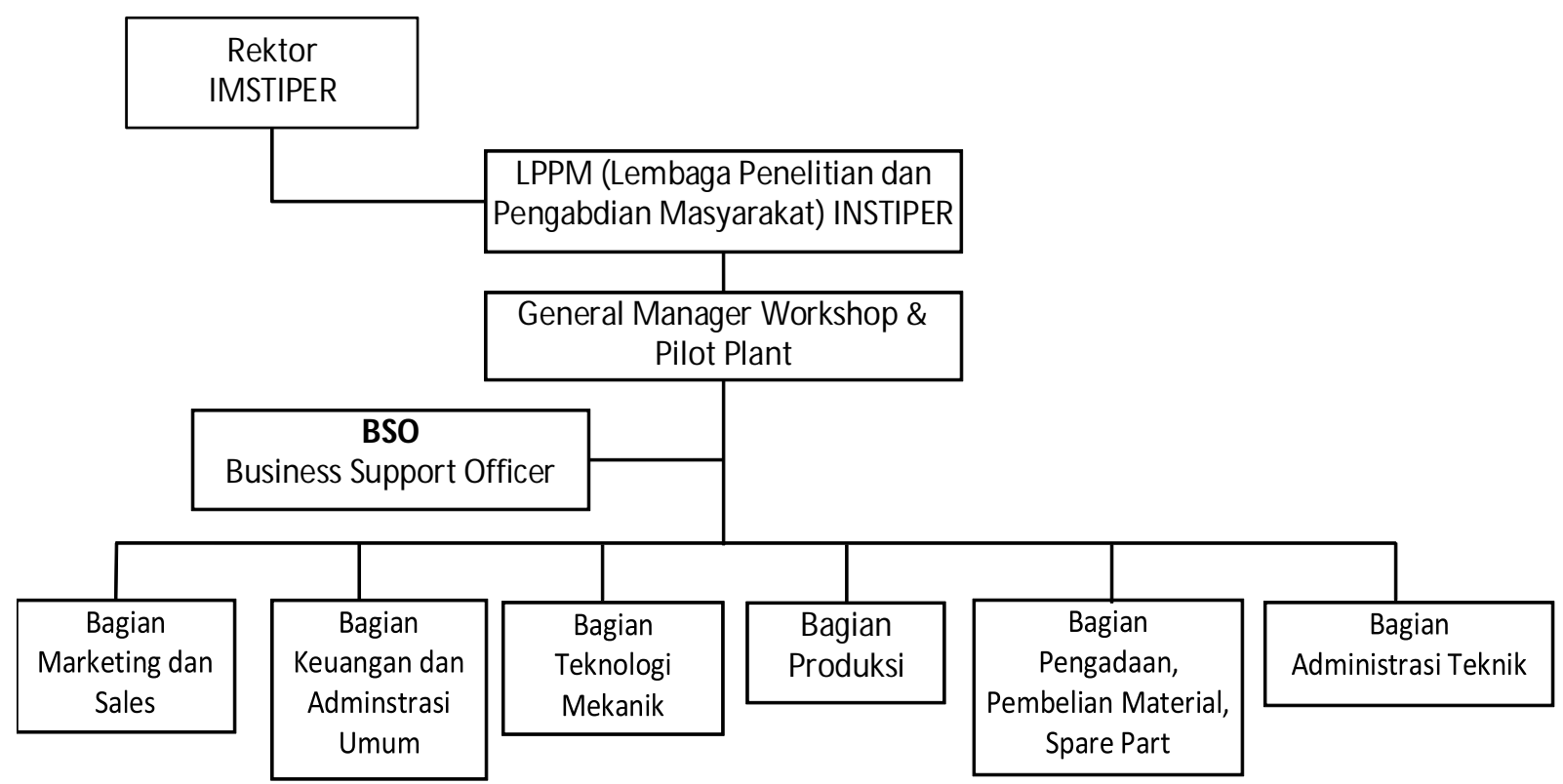

Gambar 5. Struktur organisasi pusat produksi mesin dan peralatan agroindustri

Peranan dan tanggung jawab dari masing masing PIC (Person in Charge) dideskripsikan sebagai berikut: (1) General Manager Workshop \& Pilot Plant yang bertanggung jawab untuk pelaksanaan proyek dari awal sampai akhir. Dan memiliki peranan untuk mengorganisir seluruh PIC dalam struktur organisasi IPM; (2) BSO (Business Support Officer) yang membuat jadwal dan agenda pelaksanaan kegiatan serta membuat laporan kegiatan kemajuan kepada tim; (3) Bagian Produksi yang bertanggung jawab kepada proses produksi dari peralatan yang dibuat serta QC (Quality Control) dalam proses (In Process-QC); (4) Bagian Pengadaan dan Pembelian Material yang bertanggung jawab untuk mencari suplier dengan pertimbangan kecepatan penyediaan material dan harga. Serta pembelian material dan spare part berdasarkan suplier yang dipilih. Juga bertanggung terhadap kualitas material dan spare parts yang diterima (In-Coming Material QC); (5) Bagian Teknologi Mekanik yang bertanggujawab untuk masalah desain dan QC (Quality Control ) komponen mekanik; (6) Bagian Keuangan dan Administrasi Proyek yang bertanggung jawab dan mengelola keuangan, keluar masuknya uang serta pelaporan keuangan dan bukti-bukti transaksi; (7) Bagian Marketing dan Sales yang bertanggung jawab kepada aktivitas marketing (penjualan); (8) Bagian Administrasi Teknik yang bertanggung jawab pada engineering drawing dan shop drawing serta administrasi fabrikasi dan machining.

\section{Pemasaran}

Saat ini Unit Produksi telah memiliki posisi pasar yang jelas dan sudah mempunyai mitra kerjasama dalam penjualan dan penawaran produk, diantaranya adalah PT M itra Rekatama Teknologi untuk pemasaran mesin peralatan UMKM pangan, perbengkelan, pertanian serta PT Reka Inti Teknologi untuk pemasaran mesin peralatan perkebunan dan spare part pabrik kelapa sawit. Sedangkan untuk kegiatan pelatihan dan bimbingan teknis saat ini sudah menjalin kerjasama dengan Dirjen IKMA Kemenperin. 
ABDIMAS: Jurnal Pengabdian Masyarakat Universitas Merdeka Malang

Volume 5, No 3, November 2020: 266-278

\section{Teknik Pemasaran}

Teknik pemasaran yang digunakan dengan memaksimalkan penggunaan media antara lain leaflet, poster, brosur, spanduk, dan media elektronik seperti internet.

Khusus untuk internet, promosi dilakukan dengan mempromosikan dan menjual secara daring melalui website www.mesininstiper.com, dan pada bulan Juli sedang dilakukan pendaftaran kerjasama marketplace daring Blibli.com untuk memperluas jangkauan pasar.

\section{HASIL DAN PEMBAHASAN}

\section{Hasil}

Dari kegiatan PPUPIK yang telah dilakukan dan sedang berjalan ini telah dihasilkan barang berupa fabrikasi mesin peralatan agroindustri dan jasa berupa bimbingan teknis dan pelatihan pembuatan serta pengujian mesin peralatan industri pangan yang merupakan kerjasama dengan Ditjen IKMA Kementerian Perindustrian.

\section{Produksi dan Penjualan}

Pada tahun pertama PPUPIK (2019) telah berhasil memproduksi dan menjual beberapa produk pesanan UMKM yang ditunjukkan pada Tabel 2 .

Tabel 2. Hasil produksi dan penjualan tahun pertama (2019)

\begin{tabular}{lcc}
\hline Nama Barang & Kuantitas & Satuan \\
\hline Silinder press hidrolik & 1 & unit \\
Power pack hidrolik & 1 & unit \\
Screw conveyor & 1 & unit \\
Feed Mixer Horizontal & 1 & unit \\
Mesin roaster kopi kap 1 kg & 1 & unit \\
Mesin roll pipa & 1 & unit \\
\hline
\end{tabular}

Sedangkan pada tahun kedua (2020) telah diproduksi dan dijual produk seperti yang ditunjukkan pada Tabel 3.

Tabel 3. Hasil produksi dan penjualan tahun kedua (2020)

\begin{tabular}{lcc}
\hline \multicolumn{1}{c}{ Nama Barang } & Kuantitas & Satuan \\
\hline Alat Kendali suhu oven roti & 5 & Unit \\
Mesin Roll pipa hidrolik & 1 & Unit \\
Timbangan digital & 2 & Unit \\
Power pack hidrolik & 1 & Unit \\
Mesin roaster kopi kap $5 \mathrm{~kg}$ & 1 & Unit \\
Mesin roll pipa & 1 & Unit \\
\hline
\end{tabular}





Gambar6. Kegiatan pembuatan horizontal feed mixer
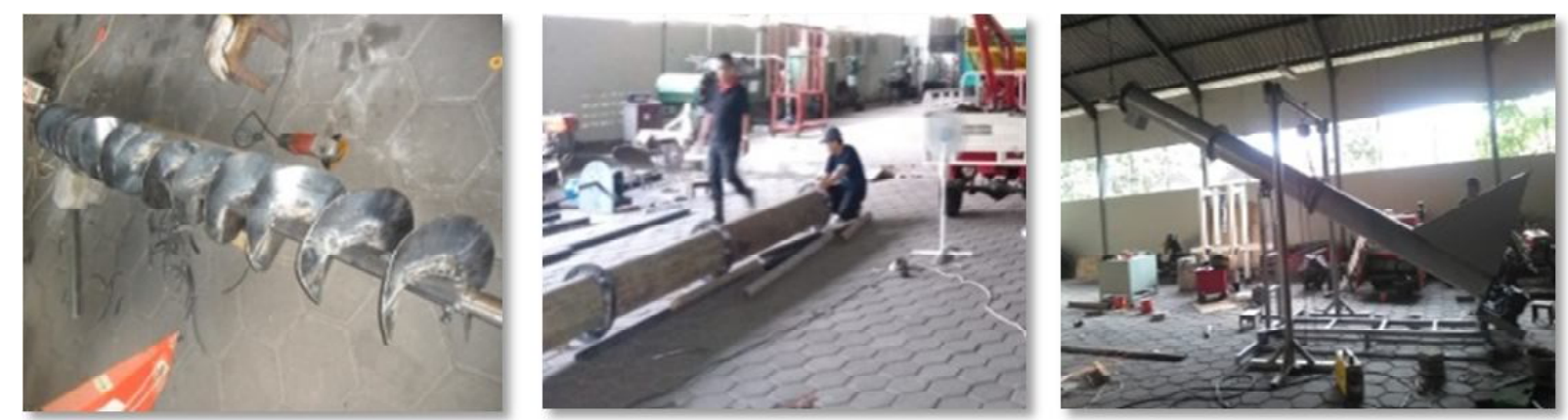

Gambar 7. Kegiatan pembuatan screw conveyor


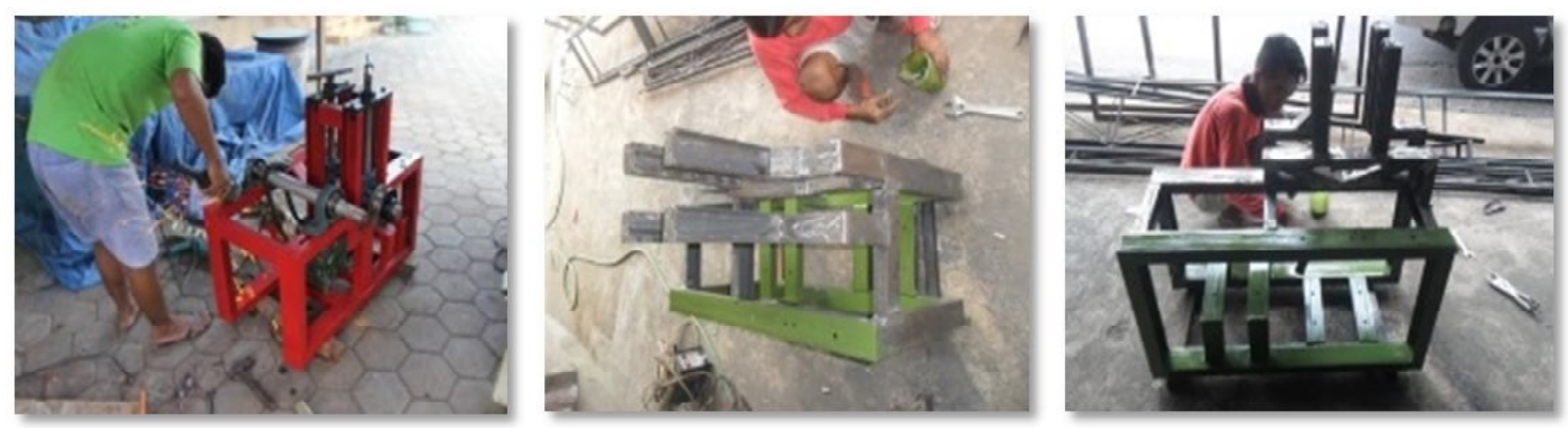

Gambar 8. Kegiatan pembuatan mesin roll pipa

\section{Uji dan Pelatihan}

Jasa uji, pelatihan yang telah berlangsung sejak mengikuti kegiatan PPUPIK ini dari tahun 2019 berkat kerjasama dangan Drijen IKMA, Kementerian Perindustrian, berupa bimbingan teknis pembuatan mesin sangrai kopi oleh UKM yang berorientasi ekspor yang diikuti dua tenant dari CV Saya Cinta Kopi, Bandung dan PD Karya Mitra Usaha, Bogor. Kegiatan ini dilaksanakan di Instiper Yogyakarta dari tanggal 7-11 Oktober 2019 (Gambar 9).
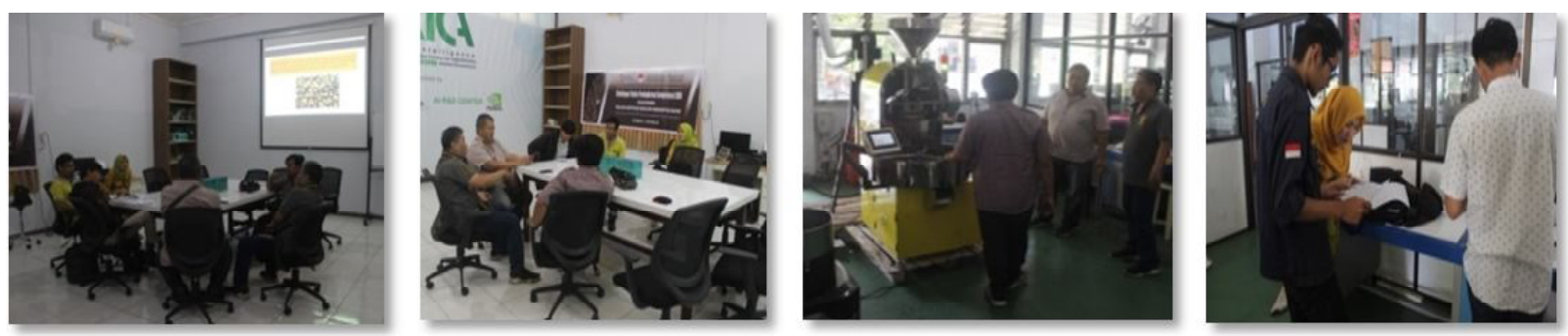

Gambar 9. Kegiatan pelatihan pembuatan mesin roaster kopi berorientasi ekspor (kerjasama Kementerian Perindustrian)
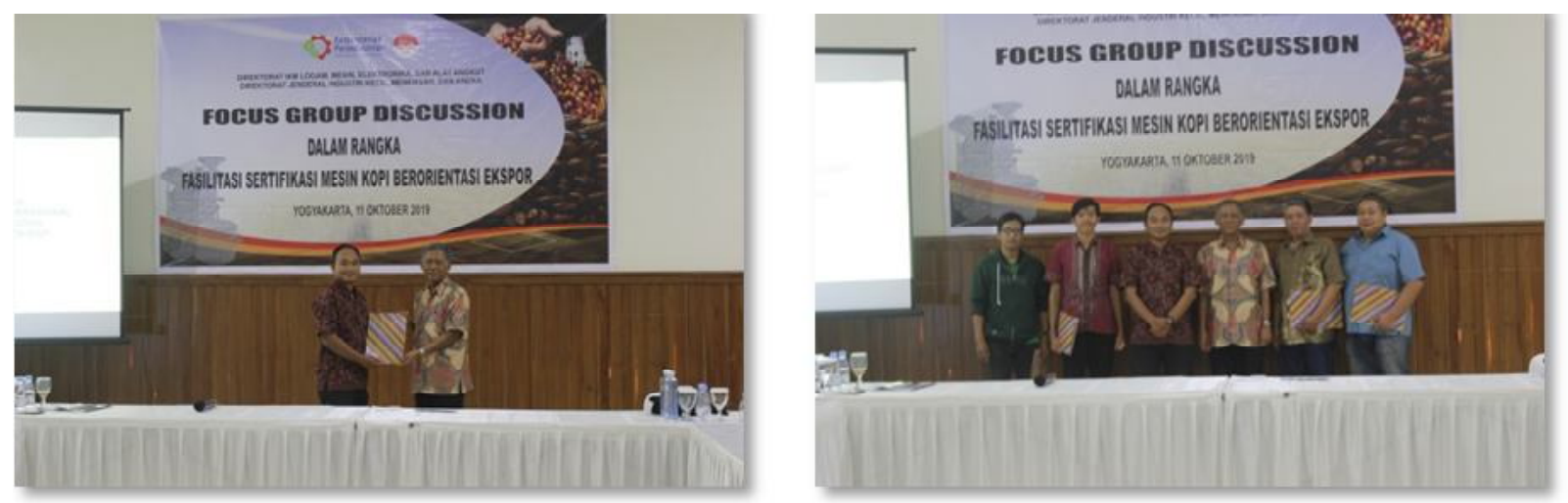

Gambar 10. Kegiatan FGD pelatihan pembuatan mesin roaster kopi berorientasi ekspor dan penyerahan sertifikat ke tenant (kerjasama Kementrian Perindustrian) 
Uji mesin sangrai kopi dari tenant dari CV Saya Cinta Kopi, Bandung dan PD Karya Mitra Usaha, Bogor (Gambar 11).


Gambar 11. Kegiatan uji mesin sangrai kopi

Kerjasama dengan Kementerian Perindustrian Dirjen IKMA, Direktorat LMEA (Industri Kecil dan Menengah, M esin, Logam, Elektronika dan Alat angkut) untuk uji mesin penggoreng dan pelatihan pembuatan mesin penggoreng untuk UMKM di Desa Kedungsuren Kabupaten Kendal Jawa Tengah (Gambar 12).
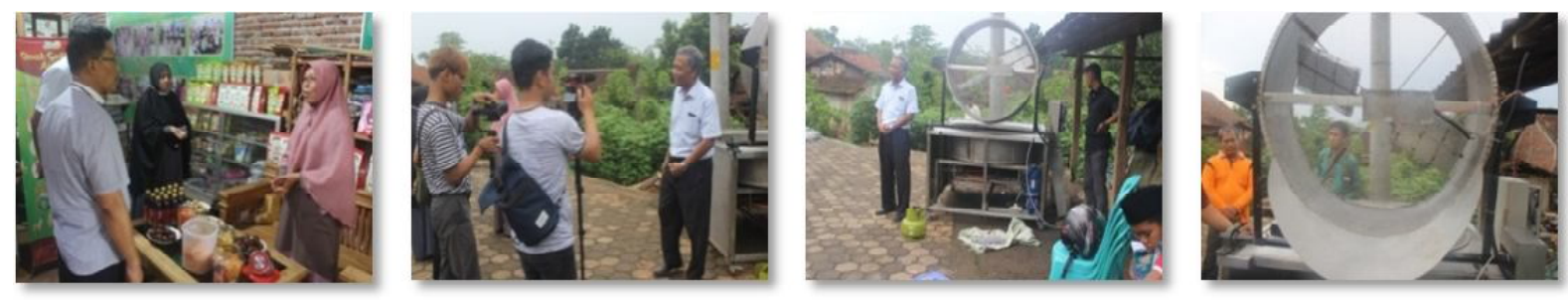

Gambar 12. Kegiatan pelatihan pembuatan mesin penggoreng untuk UM KM (kerjasama Kementrian Perindustrian)

Uji material bahan untuk mesin sangrai yang meliputi uji komposisi kimia dan uji kapasitas kalor.

\section{Pembahasan}

\section{Hasil Produksi dan Penjualan}

Dari kegiatan produksi ini telah dapat meningkatkan pengetahuan pelaksana kegiatan terutama dari mahasiswa Program Studi Teknik Pertanian tentang proses produksi maupun proses fabrikasi (manu- 
ABDIMAS: Jurnal Pengabdian Masyarakat Universitas Merdeka Malang

Volume 5, No 3, November 2020: 266-278

facturing) mesin peralatan agroindustri terutama industri pangan. Dengan terjun dan terlibat langsung dalam proses fabrikasi tersebut, maka mahasiswa yang terlibat memiliki bekal keterampilan sebagai bekal apabila mereka terjun ke dunia agroindustri setelah lulus nanti. Selain ketrampilan dalam fabrikasi, peningkatan pengetahuan juga diarahkan dalam organisasi dan manajemen industri secara praktis yang berbeda dengan teori yang pernah dipelajari.

Sedangkan hasil penjualan dapat digunakan untuk menambah pemasukan dari perguruan tinggi dan sebagi modal dari Unit Produksi Mesin Peralatan Agroindustri untuk mengembangkan varian produk dan memperluas jaringan pemasaran.

\section{Hasil Pelatihan dan Uji}

Dari hasil FGD (Focus Group Discussion), para tenant dan peserta pelatihan sangat puas terhadap materi yang disajikan. Para peserta tersebut juga sangat antusias dengan mengikuti kegiatan dari awal hingga akhir. Hasil yang telah dicapai pada pelatihan ini adalah para peserta bertambah pengetahuannya tentang berbagai logam yang diperuntukkan untuk industri pangan (food grade), pengetahuan tentang sifat-sifat logam terhadap panas untuk pengolahan pangan dan mengetahui cara pembuatan mesin peralatan industri pangan yang baik dan terstandar oleh Kementerian Perindustrian.

Dari hasil pengujian mesin peralatan industri pangan yang diajukan, diberikan koreksi-koreksi kesalahan yang secara tidak disadari sering dilakukan oleh para pembuat mesin peralatan industri pangan. Dengan demikian para pembuat mesin peralatan industri pangan bertambah pengetahuannya tentang standar baku mesin peralatan industri pangan.

\section{Manfaat Kegiatan}

Dampak ekonomi setelah kegiatan PPUPIK ini sesuai dengan rencana luaran kegiatan. Diantaranya, peningkatan daya saing unit usaha di perguruan tinggi berbasis produk intelektual dosen diindikasikan dangan: (1) Jumlah varian produknya meningkat; (2) Peningkatan kualitas produk pada tahun kedua, atau setelah kegiatan PPUPIK ini adalah penggunaan teknologi industri 4.0 yang diaplikasikan pada beberapa produk yang ada; (3) Peningkatan arus kas dari tahun 2014 hingga PPUPIK 2020. Kemudian peningkatan pengetahuan praktis proses manufaktur dan pengetahuan bisnis berbasis teknologi bagi mahasiswa semester akhir Program studi teknik pertanian. Selain itu, tambahan pemasukan bagi Perguruan Tinggi Instiper.

\section{Kendala}

Kendala dan hambatan yang dihadapi dalam menjalankan kegiatan PPUPIK terutama pada awal tahun kedua (tahun 2020) antara lain adalah terhambatnya produksi dan penjualan mesin peralatan agroindustri akibat lesunya perekonomian mitra karena terdampak pandemi COVID-19.

Namun kendala tersebut dapat diatasi dengan langkah strategis penjualan produk dilakukan secara daring dalam bentuk skema yang ditawarkan Kemenperind Pameran dan Hub Virtual Mesin Peralatan Tepat Guna Di Platform Blibli.com. 


\section{SIMPULAN DAN SARAN}

\section{Simpulan}

Program Pengembangan Usaha Produk Intelektual Kampus (PPUPIK) di Institut Pertania Stiper telah berhasil mendirikan Unit Produksi Mesin Peralatan Agroindustri sebagai lembaga usaha untuk menambah pemasukan kampus dan tempat pelatihan wirausaha bagi mahasiswa semaster akhir. Lembaga ini telah berhasil memproduksi dan menjual 17 unit mesin peralatan agroindustri dan telah mengadakan empat kali pelatihan dalam kurun waktu bulan Mei 2019 hingga bulan Juli 2020. Hasil yang dicapai telah berhasil meningkatkan pengetahuan tentang produksi mesin peralatan agroindustri pangan bagi mahasiswa dan mitra peserta pelatihan.

\section{Saran}

Disarankan melibatkan juga BUMD kabupaten/BUMD provinsi, Pemda kabupaten melalui dinas terkait dalam mengenalkan produk ke masyarakat dan ke pelaku usaha UMKM pangan. Selain itu juga perlu pendekatan ke koperasi dan UMKM industri pangan secara langsung.

\section{UCAPAN TERIMA KASIH}

Ucapan terima kasih atas dukungan dana dan fasilitas kegiatan kepada Deputi Bidang Penguatan Riset dan Pengembangan, Kementerian Riset dan Teknologi/Badan Riset dan Inovasi Nasional; Lembaga Layanan Dikti V; LPPM Institut Pertanian Stiper; Dirjen Industri Kecil Menengah dan Aneka, Kementerian Perindustrian; mitra produksi dan penjualan.

\section{DAFTAR PUSTAKA}

Afrianto, B. (2010). Hubungan prestasi belajar manajemen industri dengan minat berwirausaha mahasiswa. Disertasi. Pendidikan Teknik Mesin Fakultas Teknik Universitas Negeri Semarang.

Erlindawati, Safitri, A., Iswani, S., Syambarkah, A., \& Indrajaya, I. (2011). Sistem manajemen mutu $3 Q$ pada CV. Megarasa (usaha sari buah jeruk). Manajemen Mutu dan Industri Pangan, 18(1). https://cyberpustaka.wordpress.com/nomor-dan-volume/76-2/

Hariyanto, S., Yuniawan, D., \& Putra, A. F. (2019). Implementasi mesin sangrai kopi pada UKM kopi bubuk "Bias Kahyangan" di Desa Arjowinangun - Kota Malang. Abdimas: Jurnal Pengabdian Masyarakat Universitas M erdeka M alang, 4(1), 1-6. https://doi.org/10.26905/abd imas.v4i1.3231

Maligan, J. M ., \& Hermanto, M. B. (2017). introduksi teknologi mekanis untuk meningkatkan efisiensi, kapasitas produksi dan mutu keripik di UKM Kabupaten Blitar. Teknologi Pangan: Media Informasi dan Komunikasi IImiah Teknologi Pertanian, 9(1), 87-95. https://doi.org/10.35891/tp.v9i1.913

Mengani. 2019. Varietas Kopi, Metode Pengolahan, dan Pengaruhnya terhadap Cuptaste. Indonesia: Senja Kala the Third Wave Coffee.

Nasution, T. H., Putramas, A., So eharwinto, Fahmi, \& Siregar, I. (2018). Automatic coffee roaster design using Arduino. AIP Conference Proceedings 2044, 020015. https://doi.org/10.1063/1.5080068 


\section{ABDIMAS: Jurnal Pengabdian Masyarakat Universitas Merdeka Malang}

Volume 5, No 3, November 2020: 266-278

Rahayu, S. Y. S., \& Rustiani, E. (2013). Reduksi kadar logam berat dalam Kijing Taiwan Anodonta Woodiana agar menjadi bahan pangan konsumsi yang aman. Fitofarmaka:Jurnal IImiah Farmasi, 3(1), 184- 192. https://doi.org/10.33751/jf.v3i1.174

Sufiyanto, S., \& Andrijono, R. D. (2020). Analisis roll bending process pada square pipe dengan desain flexible roll. ROTASI, 22(3), 169-179. https:// doi.org/10.14710/rotasi.22.3.169-179

Sundari, D., Hananto, M., \& Suharjo. (2016). Kandungan logam berat dalam bahan pangan di kawasan industri kilang minyak Dumai. Tesis. Universitas Muhammadiyah Yogyakarta. 